\title{
Making Sense of Good Life: Local Modernity from a Traditional Industrial-Commercial Region in Southern China
}

\author{
Luo Youmin \\ Sun Yat-Sen University
}

Based on anthropological fieldwork in a traditional industrial-commercial community in southern China, this study examines how the state and ordinary citizens imagine, perceive, and live "the good life" in different periods after 1949. It also probes into how local society and daily life is influenced by various factors including state- building, political movement, economic change, traditional culture, and individuals' choice, and so on. For the state, standards of the good life are more a series of ideologies related to modernity and modernization projects. For the community and the individual, however, ideas of the good life depend on wealth, well-being, and a sense of belonging to the community. The similarity and discrepancy of their respective pursuit make their way on modernity converge, diverge and interweave in different periods. It demonstrates the processes of pursuit of the good life by various agents are dynamic and changeable, and also the heterogeneous and uncertain features of local modernity in contemporary China.

\section{A TALE: CHOICE OF MERCEDES-BENZ OR BMW}

In academia, city and village, urbanite and villager, modernity and tradition, as a series of dualistic concepts about urbanization, are clearly defined and are supposed to be distinguished. However, in my fieldwork, I found that the boundaries between these terms are more ambiguous and complicated in social reality. We can no longer simply distinct modern from tradition, urban from rural, and urbanite from villager as well. One day in the summer of 2010, the village chief drove me to a clan ceremony. On the way we chatted about cars. The village chief was driving a domestically-produced Honda Fit. He told me that his dream was to earn more money and buy a Mercedes-Benz. I asked him why Mercedes-Benz. "It's all about prestige. For that MercedesBenz means not only you have money but also have good taste and status." After that he looked at me and smiled, "I know you girls from the city prefer the BMW. You would rather weep in a BMW than be happy on a bicycle. [1]" We both laughed. The village head's Benz would bring him fortune and status. However, in his eye, the city girl's BMW stands for a vague value that is fashion and vanity but has nothing to do with him. In a rich village of Southern China, on the way to a sacred ceremony with a history of hundreds of years, the village head whose dream is to drive a Mercedes-Benz talked about the story of BMW girl with me. This scene inspired me to 
rethink my original research problem: a progress of urbanization and modernization in a rural area. For local people, the narrative and discourse of modernity is too macro and vague to related to their lives, although they are undergoing the process of modernization and benefit from modern life. Therefore, hardly can we capture people's real lives if we still following this kind of dualistic thinking. In daily practice, local people are interested in the quest for a good life and are not concerned with what modernity or tradition is. If so, what kind of good life are ordinary Chinese people looking for? What is the meaning of good life in different periods of modernization? What is the relationship between good life and modernity?

This article focuses on how urbanization of a rural area in Southern China expresses the often complicated and dynamic relationship between locality and the state on perception and practice of good life. It explores how the paths that the state and local people interpreted and developed modernity were converge or diverge. The state favors the ideology of modernity and practices it in the form of macro projects of modernization, specifically the socialist movements and reforms. The state believes these projects would benefit all citizens. In the meantime, communities and individuals search for concrete, material well-being and a sense of belonging. They are being modernized but not in the same way that the state hopes to modernize them. The similarity and discrepancy generated from the quest for modernity has driven them negotiate with one another for decades.

\section{MODERNITY AND THE SEARCH FOR "THE GOOD LIFE"}

This article explores the perception, imagination and practice of state and local society on modernity and the good life during different periods in modern Chinese history, including socialist construction(1949-1956), the socialist movement (1957-1966), the Great Proletarian Revolution (1966-1976), the Openness and Reform (1978-2004) and social transformation (after 2004). It shows that the processes of state and local people in pursuit of the good life are intricate and dynamic, and the experience of local modernity are interwoven within various factors such as state building, local society, cultural tradition and individual choice.

The term "modern" can be traced back to the fifth century, which was primarily used as a concept of time division to distinguish the present from the past (Habermas, 1985). The discussion on modernity emerged in ninetieth century. Modernity refers to "the characteristics and states of social life and facts in modern age (Xie, 2001:25-32)". Concomitant to the industrial revolution, the movement of enlightenment, capitalism and colonialism, nation-state, urbanization and later globalization, modernity was imbued with various meanings and implications in different times and spaces. Said (1983:226-247) argued that it is a sort of reproduction of concepts in local scenarios, where the concept "travels" from one culture to the other. Similarly, with modernity as a term originating in the West, its reproduction in China has engendered a series of related knowledge and discourse, related to the perception, imagination and practice of the modern, modernity and modernization (Jacka, 2006). Therefore, the representation of modernity in China can be treated as "the product of the conjoining of modernist discourses originating in the West and native institutions, historical social conditions, and native reaction-formations" (Yang, 1994:38).

The construction of modernity in China began with the passive response to the colonial activities of Western imperialism in the early twentieth century and was embedded in the history of Chinese nation-state progress (Yang, 1996; Duara, 2008). At that time, "evolution", "modernity" and other new terms were introduced from Japanese language to the Chinese 
language (Liu, 2002:14-27). The propaganda of the "new" culture and "new" value in the May $4^{\text {th }}$ movement internalized "modernity" as a way of life and value in the public sphere (Zhang, 2009). The subsequent pursuit of modernity for Chinese intellectuals, reformers, and both of the National Party and the Communist Party mirrored the long process of modernization in China. In this process, modernity was embodied in various kinds of reforms and programs, which includes Westernization movement of the Qing government, New Life Movement of Nationalist Party and the Socialism Movement of Communist Party, and so on. Modernity as dominant ideology and metaphor of good life eventually penetrated into everyday life, which indicates the expectation of brilliant future by the national community and local public alike (Yang, 1988; Rofel, 2006).

In Aristotle's view, the notion of the good life for individuals refers to "a life of pleasant amusement; a career of public service; and a life devoted to philosophy (Hutchinson, 2006:200)." He emphasized that a good human life must be a communal life, in which "everyone, whoever he is, would do the best things and live a blessed life (Taylor, 2006:248)." However, what makes sense as the "good life" should be discussed in different socio-cultural settings. Concretely, modernization in China underwent a series of changes, from "struggle for survival," to "enrich the state and strengthen the people," It also encompassed a whole spectrum of activity that ranged from revolutionary upheaval to social movements and more gradual reform. In this process, the good life as a kind of embodiment of modernity implied a "new" social order and cultural prospect, combined with the sort of modern narratives such as "evolution, competition, creativity, democracy, science, social justice, civility, and ideal of humanity (Gao, 1999:5)". In particular, the good life for local community and individual embodied a series of ideas and activities of "living a life of fortune" (guo ri zi) (Wu, 2007), in which people pursue not only individual health, wealth and pleasure, but also communal morals, ethics, social relationships (guanxi), cultural tradition and community identity and belonging.

Looking back the process of modernization in China, a series of problems emerge if we change our perspective from macro to a micro one. Why do the nation-state and its citizens pursue modernity? What are their motivations and goals? What is the meaning of pursuit of modernity for local people who are the real actors in this movement, if the state defines modernity as "enrich the state and strengthen the people, social harmony and human development"? What is the local representation of modernity in everyday life? What is the relationship between the good life in local society and the state modernization project? Is there any tension between modernity and local tradition?

The discussion is based on an anthropological fieldwork in M region, Xiqiao town, Foshan city, during the following periods: from July to August 2009, from November to December 2009, and July 2010. I conducted fieldwork with a research team consisted of seven members. We worked on diverse dimensions of the urbanization process in $\mathrm{M}$ area. The data were collected from various channels, including formal and informal interviews with local people and state officials, combined with documents from local community and different levels of governments.

\section{REGION AND ITS HISTORY}

$\mathrm{M}$ region is under the jurisdiction of Foshan City, Guangdong Province. It is located in Xiqiao town of the Pearl River Delta and composed of $\mathrm{M}$ administrative village and $\mathrm{M}$ community (shequ). 6775 members registered in M administrative village hold an agricultural household registration and 8077 members registered in $\mathrm{M}$ community hold an industrial household registration. $M$ administrative village includes 5.3 square meters of land area and 14 
small villages. $\mathrm{M}$ community is at the center of $\mathrm{M}$ administrative village, covering 1.5 square meters. Most of people registered in $\mathrm{M}$ community are living in the villages around the community. In other word, $\mathrm{M}$ community is not a residential community, but a market area which governed under the urban administration.

The main industry in $\mathrm{M}$ region is the silk and textile industry. The area has had deep historical and geographic roots for mulberry silk production. Because of the low-lying surface and humid climate, local people invented a special agricultural model known as the "mulberry tree-based Fish Ponds" [2]. They fed silkworm and planted mulberry trees, along with developing the filature and textile industry. From the Qing Dynasty, along the banks of west and north branches of Pearl River, the rural markets for silk production developed and the chain of textile industry was established. Transactions in the textile industry had developed into a specific business network along the upper reaches of the Pearl River which connected to Jiangxi, Hunan Province and other inland regions, and stretching into Southeast Asia and Bombay through the lower reaches from Guangzhou. Its prosperity from the Qing Dynasty brought local people great wealth and glory in the early twenties century.

As a community, $M$ region has a certain social order according to the rules of lineage and business activity. Local people regarded lineage as their main organization in social life (Faure, 2009:1-14). But rather than a static principle, the lineage rules changes over time. With a way of life that combined light industry, agriculture and commerce, local people has adopted modern business practice such as share-holding system and business contract in their business activities. These practice has great influence on the cultural tradition that the lineage genealogy in the early $20^{\text {th }}$ century began to advocate the cooperation and pioneering spirit in industrial and commercial activities, and added many moral ethics that about business activities (Ye \& Zhou, 2008). The deep development of industry and commerce, intensive business chains and social relationship strengthened the local identity and communal cohesion in the lineage society.

In the early $20^{\text {th }}$ century, people living in $\mathrm{M}$ region faced some changes in their way of life. On the one hand, they still lived according to the rules of lineage and cultural tradition, although this also changed with the times; on the other hand, they absorbed some modern techniques such as machine-run filature, factory management and cooperative system to run their business. $\mathrm{M}$ region thus became a place which involved both traditional and modern factors. Living in such a commercial area, local people realized that modern strategies in business would be helpful to grasp the great opportunities in domestic and international markets that the late $20^{\text {th }}$ century presented. Meanwhile, they found that the traditional ethics, cohesion and reciprocity in the community would benefit them in the face of outside competitive trade. Hence, ideal good life for individuals gradually emerged, composed of wealth, traditional morals, community belonging, freedom of choice and flexible ways of life.

\section{STATE CONSTRUCTION AND SOCIAL REORGANIZATION: 1949-1959}

After new China was built in 1949, the state hoped to rebuild a new nation-state. An entire constructive plan that would lead people to "the good life" had been outlined by the Party. In fact, the Communist Party was confronting a dilapidated country that was devastated by decades of war. Referring to the pattern of the Soviet Union, the Party adopted macro-economic policies with the intent to rapidly reconstruct the entire nation-state. Thus, productive activities became urgent needs of governance in the first decade (Chen, 1990). However, as James Scott argued, the state knew little about the nation-state, and was, "in many crucial respects, partially blind; it 
knew precious little about its subjects, their wealth, their land holdings and yield, their location, their very identity" (Scott, 1998:2). Therefore, making the detailed of information about the country clearly and simple was the central problem of statecraft and the first step in $\mathrm{M}$ region is separating out industry, agriculture and commerce from their previously mixed and integrated situations.

In seeking to modernize the local society, the state encountered a complicated local situation. The local characteristic of mixed agriculture, textile industry and commerce challenged the statecraft. Nevertheless, the state launched two reforms that had splitted the integrated local community into two separate and independent parts. Land reform and socialist transformation of capitalist industry and commerce attempted to demarcate the boundaries between agriculture and industry, as well as rural and urban. Land reform officially started in the winter of 1950, claimed that all the lands are owned by the state and landowners should be divided into various classes according to the acreage they owned. The campaign of the socialist transformation of capitalist industry and commerce followed. Different policies were applied to various groups: 1) the property of land owners and large capitalists were confiscated; 2) the factories and enterprises of patriotic capitalists were purchased and turned into state-owned/country-owned; 3) small-scale artisans were organized into cooperative groups.

As a production and commercial center of textile industry in southern China, $\mathrm{M}$ region was not merely a rural community like most inland parts of China. Before land reform, 45,538 of the population (64.8\%) worked in accordance with the chains of mulberry tree-based fish ponds system (work team of land reform in X district of Nanhai, 1952). Moreover, a large number of people engaged in agriculture, handicraft or commerce simultaneously. It would be impossible to clearly define peasant and worker as occupations. Further, a great many lands were controlled by the lineages in the name of common property. In terms of land, the rights of ownership, development and disposal were exceedingly complicated and always involved within several lineages' internal affairs. It made the simplified principle hard to carry out. A precise classification of peasant and artisan were internally impossible, and the effort of sub-dividing people within the designated class was also intractable.

In order to achieve the goal of clearly defining political identity, the state provided local people the choice: to be a peasant or a worker? Villagers including those once engaged in silkworm feeding and fishing, artisans who lost their means of production, as well as other people of unclear identity, all confronted the same alternative: does one become a worker or a peasant? Some middle-aged inhabitants still remember this dilemma:

"We only had a little land here; some people used to do handicrafts in the household, but since the state confiscated machines, some people had nothing else to do. Also, as they had never learnt plowing, they decided to work in the factories. In many families, one member of a couple went to a factory and the other went into farming." (Interview LG, retired worker, 76 years old).

Many local people told me that they do not realize the consequences of this dualistic classification system. For them, working on agriculture or textile industry had no obvious disparity in their social status and life quality. Some people chose to work in the factories, in which most women undertook filature and spinning work, while men handled technology and repair. Meanwhile, some artisans chose to be peasants. According to official data, 43,710 people chose to be peasants, and 25,470 people went to the factories to become industrial worker (work 
team of land reform in X district of Nanhai, 1952).

By redefining the land ownership and the identifying who is peasant and who is not, the state detached agriculture from the mixed economic structure. With the policy of "planned purchase and supply" a planned economy was carried out and all private commerce was banned. The separation of agriculture and industry was completely accomplished in 1965, when the last private handicraft was shut down, marking the disappearance of each household-based textile enterprise. And the local markets of mulberry leaves, silk and cocoons no longer existed, but were replaced by kinds of supply and marketing cooperatives. The state merged small-scale and distributing textile workshops and factories into three state-owned/county-owned silk factories [3] in the following three decades and administratively defined the places where the factories located in as urban area. Therefore, $M$ region was separated as a dualistic village-city area.

By these reforms, the state changed local landscape and the cultural meanings attached to it. The former market of $\mathrm{M}$ region had previously been a place of commodity exchange and important assembly for the surrounding villages. However, the state separated the market from the villages by establishing new factories and different administrative systems. It was no longer a market but an industrial area. Thus, the administrative boundary between rural area and urban area was strictly settled. As well, the administrative system changed. The government implemented two administrative systems. In three textile factories, the city governmental system known as danwei (work unit) was set up. By contrast, the surrounding villages were regulated into layers of the People's Communes. Finally, the identity of residents was redefined. According to Land reform and the Socialist Transformation of Capitalist Industry and Commerce, local people were divided into an agricultural population and industrial population. And for each group, more classes were subdivided again, such as landlord, middle peasant and poor peasant. Following that, a dual system of urban and rural had been firmly established. These stateintroduced divisions had consequences for the way well-being and productivity was enacted and perceived.

The new government tried to reorganize the society by a new set of simplified statecraft: through land inventory, re-demarcation of districts and reclassification of the population, the state expected to understand the local society so as to effectively control it. As far as re-planning social order and daily life was concerned, the state expected that production and life be guided by absolute science and rational knowledge; through ideology and power, all individual and their personal life was brought in the logic of the state's system (Scott, 2005:1-9). However, the diversity and heterogeneity of the local society and individuals made this process difficult. The systematic chain of agriculture, industry and commerce was cut off; the free market was strictly demarcated as urban community and separated from surrounding rural areas; people's identity altered from ambiguous and multiple social dimensions to single political status.

In the first decade after 1949, the state managed to revive the local economics of textile industry, and local people were positive. Encouraged by the state, silkworm and mulberry productivity and the plant area of mulberry trees had increased rapidly. In addition, the merging of handicraft industries and the concentration of production gradually saved the textile industry from depression. Although local people could neither understand the meanings of political classification nor the definitions of identity, they felt happy because the state truly did revive the local economy as it promised. For them, the prosperity of textile industry was more real and closer than the utopian communism claimed by the state. It seemed that the good life socialism had promised was about to begin. In some sense, the prosperity of local economy in the early 1950s was attributed to supply-demand system planned and dominated by the state. Under this 
macro planned economy, the redistribution of resource was usually based upon the state interests rather than local ones, in other word, individuals may not get a suitable remuneration according to their efforts.

\section{"POVERTY" LOGIC OF SOCIALIST MOVEMENTS VS. A LOCAL DISCUSSION MEETING: 1959-1966}

In the second decade after liberation, socialism seemed to as the only definition of "the good life" in the political logic of the state (Bauer, 2004:435). From the year 1955, the state adopted a policy of "planned purchase and supply" for the silkworm and cocoon; consequently individual filature (creation of the silk fiber) completely ceased. The commercial chains were totally monopolized by the state, including the daily commodity supply. In 1958, the establishment of the People's Commune system put the peasants more firmly into the framework of the socialism system. A new life, marked with new identity and class, was initiated. The leader Mao Tse-tung, said in a speech "Apart from their other characteristics, the outstanding thing about China's 600 million people is that they are 'poor and blank'. This may seem a bad thing, but in reality it is a good thing. Poverty gives rise to the desire for change, the desire for action and the desire for revolution" (Mao, 1958). The "poor and blank" theory laid the foundation of the ideology in the first three decades.

Local people felt increasing anxiety about their daily life in this period. The pursuit of good life respectively by state and local people gradually became further removed from one another. The conflicts appeared in several socialist movements. The autonomy of local economy was impacted by the socialist nationalization and planned economy, and it also influenced desire and force of individuals to conduct production. In M region, great discrepancy of local people's choice of identity in the first decade had emerged. The workers had economic and social welfare, including commodity grain supply, free medical care, housing benefits, child education and retirement protection, etc. But the peasants were excluded from this beneficial system.

In 1959, People's Commune of $\mathrm{M}$ region held a meeting to discuss the socialism movements (work team of the socialist transformation of capitalist industry and commerce in $\mathrm{M}$ commune, 1959). Some representatives in the conference spoke frankly. The production and supply issue of provisions received the most complaint and challenge:

"The greatest disadvantages are insufficient supply of meat, so that the provisions consumed are much greater than before. Also insufficient cooking oil supply, I used to eat 27 jin (one jin = half a kilogram) rice, but now I need 50 jin to satisfy my stomach."(Q, villager $)$

"When the supply of provisions becomes insufficient, even the dog meat sells for 2.5 yuan per jin. What's more, we need provisions tickets to get it. When seeing my little children scramble for the crispy rice on the bottom of the pot, I feel grieved. My children didn't steal food before, but now they would do that."(C, villager)

Besides, with regard to the policy of the Communist Party, the resentment towards the collectivization system was revealed. It was commonly agreed that the system of collectivization caused overstaffing, waste, lowered efficiency, mono-supply of commodity and coarse quality. 
Moreover, the discrepancy between city and village increasingly loomed large:

"The commercial departments and provider were cut too much and now we need to line up and wait to buy anything. Compared to the previous life, which indeed is better?" (Y, villager)

"I have great discontentment with cooking oil; the [urban] citizen has 500 grams but we have only 50 grams each month". (L, villager)

Compared to the socialist construction in the first decade, the following socialist movements exerted negative effects on people's daily life. People's real life increasingly worsened. Local people's resentment towards the state and the collectivism policy resulted from the regression of daily life: the insufficient supply of provisions turn hunger into a common issue and the disparity of city-village dual system aggravated the situation. Free commercial activities came to a full stop, so that even daily necessities could not be regularly supplied. Moreover, the irony became that the tendency of local cadres moved toward boasting and exaggeration. Local people, especially those who were redefined as peasant thought that this kind of good life was even worse than the days before liberation:

"What time is the good time for us? Definitely it was the days before liberation. It was the time when people were living with the wealthy life, and we could buy everything we wanted in our market. People living around us admired us because of our prosperous life. As the saying goes, people would rather being a dog in $M$ region than being a human in other place." (Interview Cheng, villager, 73 years old)

From perspective of local people, the good life has broader meanings than that of the state. The multiple meanings included attributes of the free market, wealthy and respectability. However, in the ideology of the state, socialism which marked as "modern" and "socialist", as differentiated from the former "backward" and "feudal or capitalistic" became the only standard of good life. The state made the promise that the life at present is better than that in the past, and so will undoubtedly be so in the future. But for local people, the state has not brought them the expected one that promised at the beginning. Instead, imparity deepened, the daily life becomes retrograde.

By the mid 1950s and early 1960s, all kinds of social activities existed in the name of labor and other productive discourse (Xue, 1998). However, the strategic choice of dual identity in the family and the discussion held in 1959 mentioned above shows the local people's subjectivity to some degree. They questioned the socialist movements and the state's policies through their local knowledge: "Why is the discrepancy between peasant and worker greater than before the liberation?" or "Is the M region suited for grain agriculture on such massive scale?" etc. The ideological practice of the state deviated from industrial commercial tradition in the local society. With retrogression of daily life, local people were longing for the traditional life more than ever before. 


\section{DISJUNCTION IN DAILY LIFE: 1966-1976}

During the ten-year of the Great Proletarian Revolution, the highly concentrated economic system and political life guided by class struggle had penetrated most aspects of social life. Under the guidance of "breaking down the 'four olds' (old customs, old culture, old habits, and old ideas) and setting up the "four news"' (CCP, 1967), traditional culture bore the brunt: in M region, ancestral halls were converted into warehouses and schools, genealogies were destroyed, all religious activities were banned, and temples were demolished. Locals could not completely withdraw from the rigid political system; meanwhile, they adopted many strategies to face the depression of local economy and gradually achieved a breakthrough.

The monotonous and rigid planned economics couldn't inspire the enthusiasm for production. The extreme scarcity of daily necessities made people fall into poverty. However, in order to survive, the local people had to struggle their way out with even some unwilling behaviors, including theft, bribery, and abuse of power, engaging in private business and so on. According to one of the governmental researches in 1973, 10 thousand grams of fish was stolen from the pond within a year at Xiqiao (Xiqiao Commune Revolutionary Committee, 1973).

In the early 1970s, rigid social sanctions were loosened. In 1972, local government put forth a notification that village commerce was allowed in the name of "meeting the needs of people's life, consolidating collective economy (Xiqiao Commune Revolutionary Committee, 1972)." The document stated that the peasants can sell pigs, sugar cane, fish and eggs within quota. But the time, place and quantity of transaction were highly regulated. The activities that abandoning farming to do the business were strictly forbidden. In 1973, research in Xiqiao town showed $40 \%-60 \%$ of the production team was engage in sideline businesses. They "secretly dug out lotus root to sell or steal other cash crops," which were condemned by the Government's report as capitalism thinking and a departure from the ideology that "only socialism can save China. (Xiqiao Communt Revolutionary Committee, 1973)" Actually, not only peasants, but also cadres and workers began to break through the restrictions. These personal activities, which in the state's view were impure, gradually forced an opening through the rigid system network.

In this period, hatred toward the old society and the West closely linked up to the state's modern ideal, with anti-traditionalism and anti-capitalism together penetrating individuals' daily lives through mass movements. The state wished to achieve ideal and pure "socialism" via largescale mass movement, and forbade anything or anyone related to "feudalism," "capitalism," and "imperialism". Economic and cultural diversity of local social life were severely suppressed. However, individuals, as actors, still could break through some limitations - the state could define what "capitalism" is ideologically, but could not solve the food problem. Local people adopted various forms to express their dissatisfaction and resistance. Meanwhile, the rural market was revitalized with the efforts of individuals and local governments. In the name of socialist business, the rural market improved people's daily life. These policies showed people's resistance and deconstruction of the political and economic systems in a micro perspective. Although it was believed that better life only existed in the past or in the future, even now, people still chose the living logic of "with both hands, no hunger ," in between nostalgia and longing.

\section{NEW LOGIC OF REFORM: 1972-1992}

Before the Great Proletarian Cultural Revolution, the doctrine of socialist activity was 
"poverty makes reformation easy". However, the reform led by Xiaoping Deng tried to liberate the state under the rigid ideology (Zhao, 2009)." He took a serious critical retrospective of socialist practice in the past three decades and realized that the state should go out of the shadow of poverty from such a strict economic and ideological situation. He launched a series of reform in economic sphere at beginning in the late 1970s.

At its inception, people pursued informal and oftentimes illegal ways to make money, which were condemned as "evil trends (wai feng xie qi)" by the cautious local government. But soon they dived into trends of private business in the early 1980s. Reformation was such a double-edged sword that on one hand some local people had enjoyed the "sweet taste (tian tou)," on the other, some workers suffered from unemployment. The return of commercial livelihood and lifestyle had redefined the discourse of "tradition" and "modernity" in this country. The wealth of material life was already at their fingertips; however, the good life still remained a distant dream.

\section{Evil Trends (wai feng xie qi)}

In 1978, Reform and Opening-Up Policy were put forth in the Third Plenary Session of the Eleventh Central Committee. However, local officer stuck to prudence for that they couldn't understand the vague information from the state. They wondered how it was possible to maintain socialism and carry out free economy at the same time. This was really a tough problem. They condemned the phenomenon that people engaged private business as "evil trends" (Xiqiao Commune Revolutionary Committee, 1982):

"Some commune members butchered more than 80 pigs without permission. All cadres knew about it, but they thought it was a representation of emancipating the thought and letting some members get rich first. So they ignored this."

In contrast, some peasants no longer worked for the commune. They determined to go out and give a try, with the label of "selfishness" and "liberalism", which considered by local government. They were conducting "capitalistic" businesses in the flexible political environment. In 1985, the NO.1 CCP Central Document was sent out, which affirmed trial reform. The state had made its stand on reform clearly in this document, and local governments had come to realize that reformation was included in the national developmental framework. Until then, local officials started encouraging people to think innovatively. However, although some people began to initiate their business, lots of them seemed to have little confidence in the stability and sustainability of the complicated and volatile policy:

"The policy of CCP is constantly changing. In the beginning, the contract was said to be lasting only three years, and then the last year it became fifteen years. Now the year was extended again (Xiqiao Regional Committee of Nanhai.1985)."

\section{The Sweet Taste (tian tou)}

No matter how prudent and suspicious some local people were, the impact of planned policy had gradually been ceasing in Guangdong, where reform and opening-up was being pioneered. The local textile industry entered into a golden age. The state stopped the overall planning from material to sales for state-owned textile factories. The workers went out of the city to purchase raw material and made necessary market investigation on their own. The cloth became hot in the market, where cloth was in extreme shortage. Workers in the textile factories in $\mathrm{M}$ region were 
proud of their prosperity. There is still a saying that "The best is Hong Kong, then comes the Third Factory" from which we can imagine the prosperous development of the state-owned and collective textile enterprises in $\mathrm{M}$ region.

By then, technical workers in the factories spent their spare time to do "private odd jobs": some people got their own spinning machines and set up workshops in the household. Some workers stole samples from the factories and produced the cloth at a faster rate than the collective factories and launched it into the market even a week earlier. Compared to the collective factories whose bureaucratic system was complicated, the workshops were more flexible and segmented in market. Even popular cloth from Hong Kong, Taiwan and abroad was tested and adopted by technical workers and then put into production in those workshop. The women weavers went on working at their household spinning machine after formal work was completed. In the late 1980s, almost every worker in the factories had a second job. There were a total of more than 1000 private workshops in Xiqiao town in the late 1980s, and in the 1990s, the number increased to more than 3000 . Local people remembered clearly that:

"People from all over the country, even those from Xinjiang, came to buy cloth. All cloth had a market." (Interview Da, villager, 52 years old)

"People lined up carrying the gunning bag filled with money, and waited to buy cloth." (Interview Si, worker, 57 years old)

"You can earn money as long as you are willing to work. You get rich if you go ahead before others." (Interview Chen, villager, 37 years old)

\section{Go To Business (xia hai)}

The trial reform of the state was just at the starting stage, but the local society had shown vigorous enthusiasm, which had been suppressed for a long time. For individuals, the openingpolicy issued from the state has driven the prosperous growth of the local economy, and there's great opportunity for making money. The free economy brought about rapid growth in individual wealth for many. Those prudent and suspicious had witnessed that the pioneers had new houses and color TV sets, so they couldn't resist the temptation and got involved in the stream of private business. Wealth became the new social goal. Everyone's wish was "to be a boss and earn good money". A large quantity of people quit their jobs without hesitation and ran their own factories or work in the private enterprises.

The government conducted a general survey on "top-grade daily necessities" in 1982, including the quantities of bicycles, TV sets, radios, fans and rice cookers (Statistical Bureau of Nanhai, 1982); in 1985, the quantity of such necessities was more than twice that of 1982 (Statistical Bureau of Nanhai, 1985). Moreover, general survey data of 1984 showed that information came through the way of media and TV shows in Hong Kong could also be received in some people's homes (Statistical Bureau of Nanhai, 1984). They received Hong Kong TV programs in secret and were attracted to the urban life with "capitalist" characteristics. Guldin (1988) found that Hong Kong provided a model of "good life" for these areas that were undergoing modernization. He found out that Hong Kong and Guangzhou had great influence on the local language, culture and economy of the southern Chinese village regions. Especially, the modern management system and techniques were introduced into the private enterprises as more and more compatriots in Hong Kong and Macao came back to visit relatives. Meanwhile, the 
pursuit of modern life was more associated with individual effort and private wealth, and no longer tightly interrelated with the state's modernization projects.

\section{Unemployment (xia gang)}

The private enterprises developed prosperously, while the state-owned and collective factories encountered too many problems of "capital shortage, insolvent inventories, lack of competencies and poor management (Xiqiao Town Committee, 1989)." Obviously, as they couldn't compete with the vigorous private enterprises in the late 1990s, they went bankrupt, with factories and dormitories up for rent and the machines and implements up for sale. At the same time, most of the workers were no longer as proud as before. People knew that the collective times of "eating from the same big pot" had gone forever. The income and social status after unemployment cannot be compared with the golden age. It's hard for the unemployed to get used to it. However, since the booming private enterprises provided new opportunities for them, the situation did not get very acute like other places in China. The workers from the state-owned enterprises gradually broke away and went to the private enterprises or went to run their own companies.

With the bankruptcy of the three collective factories, danwei (work unit) as a system of social control in factories also disintegrated in the late of 1990s. Therefore, danwei did not influence people's daily life as before. As a tool used by the state to take control of the individual (Li and $\mathrm{Li}, 2000$ ), its disintegration led to the readjustment of the relation between the state and individuals. The state could no longer play its power by providing and reallocating the basic material needs (Yang, 1988). The historical commercial tradition of $\mathrm{M}$ region spawned new impetus in the regional economy. Locals treated the traditional production and trading of silk as the major force in the local economy. Whether willingly or unwillingly laid off, people found the return to small-scale production of textile manufacture and trading was the key path to wealth. Some elderly seemingly felt that:

"There was no difference between the private enterprises and the workshops before the liberation. Although the machine now is made of metal instead of wood, the operation is similar to the old wooden machine when we were young. The only difference is that there are no silkworms, and there is only weaving and selling of clothes. Before, there were a lot of related businesses." (Interview GS, retired cadre, 76 years old)

People generally had the feeling of "return", that is, from a strict constraint under the planned economy to the traditional community's livelihoods and lifestyle, and a return from the national collective life to the life of individuals, families, communities and social relationships. People had complex feelings regarding this, and frequently compared the current times with the prosperous silk industry of pre-liberation as "a boat of raw silk out, a vessel of silver back ". They complained about it not being as good as before, while dreaming of better future.

At this point in the 1990s, wealth became the common goal for both the state and local people, and the pursuit of good life was no longer just the implementation of the national largescale modernization projects. It was possible for people to improve their lives via a variety of social resources such as "guanxi"(Yang, 1994) and "personal favors" (ren qing), which demonstrated the pursuit of modernity was increasingly market-oriented and personalized. The state started to focus on wealth growth and further reform in political realm. The national pursuit 
of modernization paralleled the implementation of commodity economy and market economy. Meanwhile, people's personal lives had undergone tremendous changes. The new modern life became attainable that was no longer the illusory "communism", but more linked with personal ability and opportunities. Tangible personal property, whether watches, television sets, or other personal assets, were worthy of struggle and effort. Beyond material acquisition alone, people began to look forward to urban life at Hong Kong or Guangzhou for inspiration and assetbuilding and personal style, from clothing to home decoration. The pursuit of good life was gradually diversified as it shifted from materialism to more intangible values beyond simple acquisition of goods.

\section{PLIGHT OF TRANSFORMATION: 1992 TO DATE}

The state has continued to undergo a challenging time of transformation. Although people's lives had become better, the promised "good society" has not come with market economy. To some extent, a new contradiction presented itself: the prosperous market economy coupled with the absence of social life was more difficult to cope with. Economy oriented developed model has brought many social consequences. On one hand, the state hoped that by promoting industrial transform, urbanization and other modernization projects the social problem could be handled. On the other, the state is absent from social life. Local people decided to reconstruct their tradition and culture to achieve community coherence.

\section{Intense Competition in the Textile Industry}

After 1990s, the textile market no longer fell under the previous situation that "sells well as long as it was cloth". The market had higher standards of style, popularity and technique. Lowquality cloth could not sell out any more. People started to search for new business opportunities. Small private enterprises competed and merged into large powerful companies. Some factories switched to do furniture, tile and so on. The prosperity at the early stage of reform disappeared and more and more people went out of the village to start new undertakings. According to statistics of $\mathrm{M}$ region in 2008, there are more than 100 textile mills, with 4,000 to 5,000 employees. "It just costs 10,000 yuan to set up a factory in the 1980s. And it will spend around 400,000 yuan if you want to buy merely a loom now (2010)", one of my informants told me that. Due to changes in external regional conditions, domestic and international competition, the industrial development in the surrounding areas, and the popularity of commercial clustering, $\mathrm{M}$ region as a regional center or commercial center of the textile industry lost its edge. Apart from only a few operations, managed outside of well-managed and well-operated local textile enterprises, most people left the village and the textile industry in search for new business opportunities. An entrepreneur Wen told me his story:

"I started my business from 1989 and the initial fund was 70,000 yuan. Then there were nearly 20-30 factories in my village. I cannot get helping from my relatives because almost everyone has work to do in their household workshops. We hired outside people until 1998, when the local industry become recessionary. At the beginning, people were unwilling to sell their cloth because of a little bit low price. Months later, those cloths depreciated into a half price. My total loss was 20,000 at that time." 
Lots of business men experienced such a depressed situation in $\mathrm{M}$ region. Some of them thought that the textile industry in $M$ region had gradually lost vitality than before, while others still believed that there are lots of opportunities in $\mathrm{M}$ region. Qi, another entrepreneur recalled that:

"Before I initiated my own business, I was a staff in the collective factory. I learned everything about running textile industry and knew which part can get the highest profit. I spend 10,000 yuan to buy four textile machines from Guangzhou and established my own workshop in 1984. I earned more money and brought eight machines later. I focused on processing cloth because its profit was higher than cloth producing. When the collective factory broke down in 2000, I borrowed money to buy the whole collective factory and make it better year by year. And I purchased another collective factory in 2002. Now I successfully expanded my business into most parts of the textile industry chains."

In $\mathrm{M}$ region, only a few business men like Qi were winners in such an intensely competitive market. After all, as the process of transformation, the time that everyone could benefit from the prosperous market has been past. Winners, though they are very few, were survived in a competitive market. They are more rational than their pioneers, and have sophisticated experience on production, sale and service. However, they are also faced the ubiquitous challenges, which not only come from inside economics in $\mathrm{M}$ region, but also stem from outside world.

\section{Urbanization Reform}

In 2004, elsewhere in Guandong Province, Foshan City formally claimed community transformation. It is expected that the rural population will be transformed into the urban population, so as to realize the goal of urbanization. Along the way to reform, the state found that reform of economic system couldn't be isolated into component parts. Reform must comprise the entire social system (Sun, 2005). What is the goal of reform? The state started to rethink this question, and social reconstruction was once again brought forth from 2004 to date. The new social goal for the local government is "industrialization, urbanization and internationalization [4]." On the contrary, the policy was broadly resisted. The workers, who registered as urban citizens and accounted for half of the local population, are trying to transfer their identity registration into rural residents. And the peasants were unwilling to transfer their registration as urban residents. In fact, all residents' registers now are marked with "citizen", while in the villages, the local government kept two systems of register records.

"I maintain the rural register, so I can keep the house and the land; while if I transform to urban register, I might have nothing one day." (Interview H, private entrepreneur, 57 years old)

The local people prefer a rural household registration to an urban household registration. Firstly, the rural resident entitles dividends on land shares, and rural land registries allow for the lands for home construction. This is of greatest advantage in Pearl River Delta, where the cost of land is high. Secondly, rural residents have the rights to give birth to a second baby if the first is a girl. But the urban resident can only have one child. Thirdly, rural residents could also purchase 
social welfare as the same as the urban residents, which was used to the privilege of urban resident. People hope to lead a life that characterized as more certainty:

"One more choice is always good. We just want to have backup a plan. I am afraid of changeable policies". (Interview H, private entrepreneur, 57 years old)

Local people worry about the uncertainty of the future. When the boundary of rural and urban is blurred because of income and consumption, people would rather choose a life that always has a backup plan. They expect a life filled with multiple possibilities and smart strategies.

\section{Revival of Tradition}

Whether registered as a rural or urban resident, local inhabitants reminisce about traditional community life in some degree. The ancestor halls and temples are being reconstructed, and the lineage activities and ceremony resume. Folk activities such as Dragon Boat Racing and Lion Dance are being embraced by both local people and the government. The local government spends more than 100,000 yuan in such activities every year. In daily life, public activities are emerging. Local women initiate a dancing group that teaches villagers modern and traditional dance for free. Elder people organize groups to do Taichi. And the men have started a lion dancing group for competition and performance. The lineage and local charitable organization all launch kinds of activities as well. People applaud lineage ceremonies, so that on the day of April $5^{\text {th }}$ [5], even the abroad villagers will go back for the ritual, and after that, they will discuss public affairs such as community construction.

In addition, the village will hold regular activities in the name of local government, such as journeys for senior citizens, tea time for the young and so on. In this way, different groups of villagers can participate in the community's public affairs, and the traditional cultural network is revived to some extent. These activities endow ample meanings to community life, which is dedicated to traditional values and social identity. Local people are enthusiastic about the traditional collective activities, considering them a positive symbol of community cohesion. Reconstructed identity and cultural tradition has become the new local heated discussion.

In past three decades, the market economy has changed society along multiple dimensions. However, economically oriented policies alone no longer fit the multiple levels of local social life. Society needs new mechanisms for integration. Local people are not only aware of searching for new opportunities outside of their villages, but also searching for traditional values and flexible cultural networks to respond to a time marked with variability, heterogeneity and mobility. This positive awareness display the maturing of local society: they have subjectivity both in the deliberation and practice in the pursuit of the good life.

\section{CONCLUSION: GOOD LIFE - AN INCOMPLETE PURSUIT}

This article focuses on the change in the pursuit of the good life in a traditional industrialcommercial region after 1949. From the perspective of ordinary people's subjectivities, perception and behavior, it tries to unravel the dynamic process of how "the good life" pursued by state gradually becomes alienated from local people's expectation. Initially, the state carried out a series of macro policies to reconstruct local society based on project of state-building. Specifically, land reform and collectivization had changed the ways of traditional livelihood. 
Contrasting with the old society, where multiple groups were recognized, people were divided in two different classes: peasants and workers. Meanwhile, the local market area was identified as a sort of community according to urban planning. In following years, the state launched several socialist movements, which caused a huge gap between political ideology and social reality. People had to face poverty and famine during the socialist movements. "The good life" promised by the state did not come into being. Moreover, local culture and social networks were greatly impacted during the period of the great proletarian cultural revolution. People used various strategies to express their dissatisfaction of reality because there was little room for local people to struggle for good life at that time. The strict social controls were released after Open Door Policy in 1978. State, local government and individuals realized that they are partners in the pursuit of wealth. The state encouraged people to pursue the good life by themselves; therefore, the way of pursuit of the good life became diversified, instead of the socialist one set by state. China is undergoing a series of social transformation nowadays, but the road of reform becomes harder. Though people are wealthier than before, good life is still not coming according to their wishes. They feel that community life is incomplete and less than satisfactory due to lack of traditional culture and communal cohesion. Hence, reconstruction of local tradition and communal spirit, as a new target for pursuit of the good life, has gradually emerged.

What is "the good life?" The state promised a modern and brilliant future during the early years. Modernity of China was embodied as a series of grand state projects including industrialization, socialist movement, economic development and urbanization. "Enrich the state and strengthen the people" as the meaning of the good life became a unitary goal that both the state and the masses pursued. Indeed, people benefited from policies on the recovery of industrial production in the first decade. However, the reconstruction of identity, classification, division between agriculture and industry, rural and urban a few years later made local people confuse about their status. They could not understand how the worker and the peasant became very different in terms of political status and social life in such a short period. Why was commerce lasting hundreds of years in this area identified as a stigmatized "capitalist" system? And how could the government consider their pursuit of wealth and a good life as "speculation" or "selfishness"? When they realized that the imagination and practice of modernity conducted by state could not bring what they wanted, they attempted to construct a new life according to their own ideals. They were no longer influenced by changeable state policies. They began to rethink meanings of the good life for both individual and community, based on their life experience. Therefore, the pursuit of modernity has multiple dimensions. It is deeply involved in state construction (Rofel, 2006:17), as well as in the context and self-constructs of individuals (Giddens, 1998:216).

All in all, the process of pursuit of good life reflects how modernity was perceived, imagined and practiced in Southern China. The multiple dimensions of the good life indicate the heterogeneous modernity in China. The state attempted to reconstruct a "modern" social order according to an ideological system of opposites: such as "New" vs. "Old" and "Socialist" vs. "Capitalist". Under such a political logic, people's material and intangible needs were treated as a foundation for an ambitious state politics (Farquhar, 2002:101). However, the ideology of Chinese socialism faced numerous challenges in local society. The state claimed to liberate individuals from traditional bondages such as family, kinship and local lineage, but the result is that local people were embedded into another authority: the modern nation-sate (Yang, 1994). From the macro narratives of state to the micro experience of individuals, both the state and the masses gradually realized that there is no simple existence of so-called "western" or "eastern" 
modernity (Rofle, 2006). In fact, the state failed to provide "the good life" for local people: "People need not only stable foods but community, not only nutrition but the special delicacies that can support a ritual life and be exchanged among townspeople (McFarquhar, 2002:101 )." Tangible properties, as well as individual emotion, community cohesion and sense of belonging are equally important. In addition, changeable meanings of good life imply the fluidity and uncertainty of modernity in Southern China. In this case, the local socio-cultural experiences present us with various dimensions and vivid pictures of modernity. After all, the pursuit of the good life is ongoing process, so we can continuously explore its meaning trough the local lens.

Acknowledgement: This paper is based on fieldwork research supported by Dr. Yang Xiaoliu's research project on urbanization of Foshan city. I would like to thank Yang's guidance in my fieldwork research. Also, I would like to thank Professor Zhou Daming and Professor Tian Guang for their kind help. Moreover, Dr. Duan Ying is highly appreciated for his very insightful and critical comments on this paper. Finally, I am grateful to Dr. Eitzen Hilda for her great efforts on editing this paper.

\section{ENDNOTES}

[1] This is from the most popular TV show "If You Are the One" in contemporary China, which provides a platform for people to find their Mr. Right and Miss Right. A girl candidate in the show announced her criteria of selecting her Mr. Right, saying that she would rather weep in a BMW than be happy on a bicycle-borrowed from Patrizia Reggiani, Maurizio Gucci's wife's talk "I would rather weep in a Rolls-Royce than be happy on a bicycle"-which arouses heated discussion on the topic of "mammonism" and personal values in contemporary China.

[2] Mulberry Tree-based Fish Ponds is a scientific ecosystem in Pearl River Delta, in which the mulberry leaves are fed to silk-worms and silkworm excreta to fish, with mud from the fish pond used as fertilizer for mulberry trees. This industry characterized by its complex and diversified cycle. See Zhong, 1982.

[3] The names of these three factories were: the First Silk Textile Factory of Nanhai, the Second Silk Textile Factory of Nanhai, and the Third Silk Textile Factory of Nanhai.

[4] The new slogan from the internet article "Foshan, zhi hui zhuan xing, wen hua xian xing" (Foshan, Wisdom Transformation, Culture Goes First). Li Xiaoling. 2010.10.22

At http://epaper.nfdaily.cn/html/2010-10/22/content_6889110.htm

[5] This is a traditional Chinese festival around April 5th. People remember and honor their ancestors at grave sites on this day.

\section{REFERENCE}

Bauer, Wolfgang. (2004). China and the Search for Happiness: Recurring themes in four thousand years of Chinese cultural history [Chinese Version]. Jiangsu: Jiangsu Renmin Chubanshe.

CCP. (1967). "zhong gong zhong yang guan yu wu chan jie ji wen hua da ge ming de jue ding" (Decision on the Great Proletarian Cultural Revolution). People's Daily. August 9.

CCP. (1985). “"zhong gong zhong yang, guo wu yuan guan yu jin yi bu huo yue nong cun jing ji 
de shi xiang zheng ce" (State Council's Ten Policies of Further Stimulate the Village Economic).

Chen, Jinyong. (1990). "shi xi she hui zhu yi guo jia cheng shi hua de te dian" (Analysis of the characteristics of urbanization in socialist countries). Chinese Journal of Population Sciences, Vol.21. No. 6: 6-12.

Duara, Prasenjit. (2009). Questioning Narratives of Modern China [Chinese Version]._Jiangsu: Jiangsu Renmin Chubanshe.

Farquhar, Judith. (2002). Appetites: Food and Sex in Postsocialist China. Durham \& London: Duke University Press.

Faure, David. (2009). Emperor and Ancestor: State and Lineage in South China [Chinese Version]. Jiangsu: Jiangsu Renmin Chubanshe. p.1-14.

Gao, Ruiquan. (1999). "zhong guo xian dai jing shen chuan tong” (China's Modern Spiritual Tradition). Shanghai: Dongfang Chuban zhongxin.

Giddens, Anthony. (1998). Modernity and Self-identity: Self and Society in the Late Modern Age [Chinese Version]. Beijing: Sanlian shudian.

Guldin E., G. (1988). “xiang cun du shi hua: Xianggang, Guangzhou he zhu jiang san jiao zhou" Rural Urbanization: Hong Kong, Guangzhou and Pearl River Delta. Open Times. NO.12: 22-25.

Habermas, Jurgen. (1985). “Modernity-An Incomplete Project”, In Hal Foster. ed., Postmodern Culture, London: Pluto Press.

Hutchinson. (2006). Barnes, Jonathan ed. The Cambridge Companion to Aristotle. Beijing: Sanlin Shudian.

Jacka, Tamara. (2006). Rural Women in Urban China: Gender, Migration, and Social Change. Armonk, N.Y.: M.E. Sharpe, Inc.

Jin, Yaoji. (1996). "lun zhong guo de 'xian dai hua'yu 'xian dai xing'” (On China's 'Modernization' and 'Modernity'). Journal of Peking University 1: 20-27.

Li, Hanlin and Li, Lulu. (2000). "dan wei cheng yuan de man yi du he xiang dui bo duo gan" (The Sense of Satisfaction and Dissatisfaction in Dan Wei). Chinese sociological research NO.2:1-17.

Liu, Lydia H. (1995). Translingual practice: Literature, National Culture, and Translated Modernity China, 1900-1937 [Chinese Version]. Beijing: Sanlin Shudian. p.14-27.

Mao, Tse-tung. (1958). Introducing a Co-operative. Selected Works of Mao Tse-tung. Vol. VIII. pp. 157-159. 
Rofel, Lisa. (2006). Other Modernities: Gendered Yearnings in China after Socialism [Chinese Version]. Jiangsu: Jiangsu Renmin Chubanshe.

Said, Edward W. (1983). The World, the Text and the Critic. Cambridge, Massachusetts: Harvard University Press. pp. 226-247.

Scott, James C. (1998). Seeing Like a State: How Certain Schemes to Improve the Human Condition Have Failed. New York, Yale University Press. p.1-9.

Statistical Bureau of Nanhai. (1982). "ji ti, si ren xian you fang wu ji zhu yao gao dang sheng huo yong pin pu cha biao" (Collective and Private House and Main Top-grade Daily Necessity Survey).

Statistical Bureau of Nanhai. (1984) “quan qu dian shi ji diao cha biao” (Survey on TV Sets in Nanhai).

Statistical Bureau of Nanhai. (1985). "nan hai xian cheng xiang jia ting nai yong xiao fei pin yi ci xing diao cha biao" (Durable Household Consumable in the City and Village in Nanhai).

Sun, Liping. (2008). "she hui zhuan xing: fa zhan she hui xue de xin yi ti"(Social Transformation: New Issues in the Field of the Sociology of Development. Open Times. NO.2:57-72.

Taylor, C.C.W. (2006). Barnes, Jonathan ed. The Cambridge Companion to Aristotle. Beijing: Sanlin Shudian. 233-258

work team of land reform in X district of Nanhai. (1952). "nan hai X qu di er pi shi qi ge tu gai xiang hu kou ji tu di tong ji biao"'(Statistics of Registration, Population and Land Own of the Second Group of Seventeen Villages after Land Reform in X District of Nanhai). November 12.

work team of land reform in X district of Nanhai. (1952). "di X qu di er pi tu gai shi qi ge xiang ge jie ceng hu kou, ren kou tu gai qian zhan you tu di tong ji biao" (Statistics of Registration, Population and Land Own of the Second Group of Seventeen Villages before Land Reform in X District). October 19.

work team of the socialist transformation of capitalist industry and commerce in M Commune. (1959). "1959 nian M gong shang jie she hui zhu yi jiao yu xun lian gu gan gong zuo zong jie" (Work Summary of Socialism Education Training for the Industrial and Commercial Practitioner in M Region in 1959). October 18.

Wu, Fei. (2007). "lun 'guo ri zi"”(On "Living a Life of Fortune"). Sociological Studies. No.6: 6685 .

Xie, Lizhong. (2001). "'xian dai xing' ji qi xiang guan ci yi bian xi" (Understanding Words relative to "Modernity"). Journal of Peking University (Humanistics and Social Sciences)_Vol.38. General No.207. No.5: 25-32. 
Xiqiao Commune Revolutionary Committee. (1972). "guan yu dang qian nong mao shi chang guan li de yi xie gui ding de tong zhi” (Notification on Current Agricultural Market Management).

Xiqiao Commune Revolutionary Committee. (1973). "yi jie ji dou zheng wei gang, zhang wo tang yu, sang yu sheng chan zhu dong quan” (In the Frame of Class Struggle, Grasp the Initiative of Pond Fishing and Mulberry Fishing Productivity).

Xiqiao Commune Revolutionary Committee. (1982). "tong yi si xiang, zhang wo zheng ce, jia qiang nong cun lao dong li de guan li, da ji wei fa huo dong”(Unity of Thinking and Master Policies to Strengthen the Management of the Rural Labor to Ban Illegal Activities).

Xiqiao Regional Committee of Nanhai. (1985). "xi qiao qu xuan chuan guan che ba wu nian zhong yang yi hao wen jian de shi dian gong zuo qing kuang” (Trial Work Situation of Publicizing and Implement of the CCP Central Document NO.1 in Xiqiao Town). February.

Xiqiao Town Committee. (1989). "xi qiao zhen zhen cun gong qi ye qing kuang diao cha" (Industrial Enterprise Survey in Xiqiao).

Xue, Fengxuan and Cai, Jianming. (1998). "yan jiu zhong guo cheng shi hua li lun xue pai shu ping" (A Review of the Theories and Hypothese on Chinese Urbanization). Geographical Research vol. 17(2): 208-216.

Yang, Mayfair. (1988). "The Modernity of Power in the Chinese Socialist Order". Cultural Anthropology.VoL.3 (4): 408-427.

Yang, Mayfair. (1994). Gifts, Favors and Banquets: The Art of Social Relationships in China. N.Y.:Cornell University Press.

Yang, Mayfair. (1996). "Tradition, Traveling Theory, Anthropology and the Discourse of Modernity in China”, in Henrietta L. Moore ed. The Further Anthropological Knowledge, N.Y.: Routledge p.93-114.

Ye, Xian'en and Zhou, Zhaoqing. (2008). "shen tou shang pin yi shi de zhu san jiao zong zu lun li" (Commercialized Lineage Ethics in Pearl River Delta). South China Review. Vol.(2-3): 92-96.

Zhao, Changwei. (2009). "lun Deng Xiaoping gai ge kai fang shi yu zhong de zhong guo she hui zhu yi xin li nian" (New Perspective of China's Socialist Concept in Deng Xiaoping's Ideology of Reform and Opening up). Contemporary World \& Socialism. No.2: 99-102.

Zhang, Xudong. (2009). "'wu si 'yu zhong guo xian dai xing wen hua de ji jin quan shi xue" ("The 4th. May Movement" and Interpretation of Cultural Modernity of China). Journal of Modern Chinese Studies. NO.1:13-18. 